\title{
Thermodynamic and Hydrodynamic Properties of Cellulose Diacetate-Dimethylacetamide Solutions
}

\author{
Kenji KAMIDE and Masatoshi SAITO \\ Textile Research Laboratory, Asahi Chemical Industry Company, Ltd., \\ Takatsuki, Osaka 569, Japan.
}

(Received November 13, 1981)

\begin{abstract}
Viscometric and light scattering investigations were carried out on cellulose diacetate (degree of substitution, $\mathrm{DS}=2.46$ ) in dimethylacetamide (DMAc) at $25^{\circ} \mathrm{C}$. The following molecular weight dependence of limiting viscosity number $[\eta]$, radius of gyration $\left\langle S^{2}\right\rangle_{z}^{1 / 2}$ and Flory's viscosity parameter $\Phi$ were obtained: $[\eta]=1.34 \times 10^{-2} M_{w}^{0.82}\left(\mathrm{~cm}^{3} \mathrm{~g}^{-1}\right),\left\langle S^{2}\right\rangle_{z}^{1 / 2}=$ $0.68 \times 10^{-8} M_{w}{ }^{0.53}(\mathrm{~cm})$, and $\Phi=5.15 \times 10^{21} M_{w}{ }^{0.23}$. Draining effect was not negligible for this system. The unperturbed chain dimension $A$ was determined by methods $2 \mathrm{~B}, 2 \mathrm{C}, 2 \mathrm{E}, 2 \mathrm{~F}$, and $2 \mathrm{G}$ proposed previously [K. Kamide and Y. Miyazaki, Polym. J., 10, 409 (1978)]. The $A$ values obtained by methods $2 \mathrm{~B}, 2 \mathrm{C}$, and $2 \mathrm{G}$ were in good agreement with each other and the most probable $A$ value was found to be $1.98 \times 10^{-8}(\mathrm{~cm})$. The variation in $[\eta],\left\langle S^{2}\right\rangle_{z}^{1 / 2}$, and $A$ with solvent is discussed in terms of the dielectric constant of the solvent and also the chemical shifts of the $O$ acetyl methyl and hydroxyl groups.

KEY WORDS Thermodynamic Property / Hydrodynamic Property / Cellulose Diacetate / Mark-Houwink-Sakurada Equation / Flory Viscosity Parameter / Unperturbed Chain Dimension /
\end{abstract}

Cellulose acetate (CA) with different degrees of substitution (DS) constitute a series of polymers whose molecular properties have not been systematically explored, mainly because of the experimental difficulty in removing gel-like materials from the solutions. Consequently, the molecular characterization of CA has been a subject of considerable interest in our laboratory ${ }^{1-21}$ for the past ten years, and dilute solutions of this polymer have been extensively studied by light scattering, membrane osmometry, viscometry, gel-permeation chromatography, ultracentrifugation, thin-layer chromatography, and nuclear magnetic reasonance.

By these studies the characteristic features of CA solutions have been progressively made clear, especially with regard to the following points: (1) the unperturbed chain dimensions $A$ of cellulose diacetate (CDA; $\mathrm{CA}$ with $\mathrm{DS}=2.46)$ and $\mathrm{CA}$ with $\mathrm{DS}=0.49$ vary markedly depending on the kind of solvent, being larger in a solvent with larger polarity. (2) The variation in $A$ with solvent is correlated closely to specific interactions between functional groups, such as the hydroxyl and the
$O$-acetyl groups in $\mathrm{CA}$ and solvent molecules. (3) The extent of solvation is also correlated to solvent polarity.

In the course of the above-mentioned studies, it was found that $N, N^{\prime}$-dimethylacetamide (DMAc) is a solvent which readily dissolves the CA molecule with a DS ranging from 0.49 to 2.92 . The systems of CA $(D S=2.92)$ and CA $(D S=0.49) / D M A c$ have been extensively studied in previous papers. ${ }^{9,15}$

In this article, by investigating the dilute solution properties of CDA in DMAc and comparing with our previous data on this polymer in acetone and tetrahydrofuran (THF) ${ }^{8}$ and on CA with different DS $\left(2.92^{9}\right.$ and $\left.0.49^{15}\right)$ in DMAc, we attempt to confirm the above-mentioned characteristic features (1) - (3) and reach a better understanding of the relationships between DS and the molecular properties of cellulose derivatives.

\section{EXPERIMENTAL}

\section{Polymer}

Five cellulose diacetate fractions $(\mathrm{DS}=2.46)$ pre- 
pared previously ${ }^{8}$ were used. The distribution of acetyl groups in a glucopyranose unit, defined as $\left\langle f_{k}\right\rangle$ (the subscript $k$ indicates the carbon position in the $\mathrm{Cl}$ chair conformation), was determined for all these fractions from the ${ }^{13} \mathrm{C}$ NMR chemical shift of the $O$-acetyl carbons, ${ }^{14}$ with the following results $\left\langle f_{6}\right\rangle=0.82,\left\langle f_{2}\right\rangle=0.75,\left\langle f_{3}\right\rangle=0.89$.

\section{Solvent}

DMAc was purified by drying it over phosphorous pentaoxide and was distilled immediately before use.

\section{Solution Viscosity}

DMAc solutions of CDA were prepared at $25^{\circ} \mathrm{C}$ and their viscosities were measured using Ubbelohde-type capillary viscometers. ${ }^{8,9}$ The limiting viscosity number $[\eta]\left(\mathrm{cm}^{3} \mathrm{~g}^{-1}\right)$ was determined using Huggins' plot.

\section{Light Scattering}

A procedure similar to that in previous studies $^{8,9,15}$ was employed for the optical clarification of DMAc solutions of CDA. After filtration of $0.8 \mathrm{~g} / 100 \mathrm{~cm}^{3}$ stock solutions through a 3 rd grade sintered glass filter, the solutions were centrifuged at $2.8 \times 10^{4} \mathrm{~g}$ for $1 \mathrm{~h}$ in a Hitachi model $55 \mathrm{p}-7$ automatic preparative ultracentrifuge to remove gel-like materials. By dilution of the isolated supernatant with DMAc, solutions of five different concentrations were prepared. These were filtered through a Sartorius membrane filter $(0.2 \mu \mathrm{m})$ immediately before each light scattering measurement.

The specific refractive index increment $\mathrm{d} n / \mathrm{d} c$ for CDA in DMAc at $25^{\circ} \mathrm{C}$ was determined on a Shimadzu differential refractometer model DR-4 at a wavelength of $436 \mathrm{~nm}$. The $\mathrm{d} n / \mathrm{d} c$ was $0.045\left(\mathrm{~cm}^{3}\right.$ $\mathrm{g}^{-1}$ ) for two CDA fractions with different molecular weights.

Light scattering measurements were made at $25^{\circ} \mathrm{C}$ on a FICA model 42000 photogoniometer, using unpolarized light (incident wavelength $\lambda_{0}=$ $436 \mathrm{~nm}$ ). The data obtained were analyzed according to Zimm's procedure.

\section{RESULTS AND DISCUSSION}

Results from light scattering (LS) and viscosity measurements on CDA fractions in DMAc at $25^{\circ} \mathrm{C}$ are shown in Table I, along with our previous data on the same series of CDA fractions in acetone and THF.

The molecular weight dependence of $[\eta], z-$ average radius of gyration $\left\langle S^{2}\right\rangle_{z}^{1 / 2}$, and second virial coefficient $A_{2}$ are shown in Figures 1a-1c. In our previous study, ${ }^{9}[\eta]$ was measured in DMAc for several fractions whose $M_{w}$ were determined by light scattering in acetone and THF (Table IX of ref 9). In Figure 1a, some of these data are represented by unfilled circles. Because of unexpectedly large scatter, the data for fractions EF2-10 and 3-10 shown in parentheses in Table I are omitted from this figure; $[\eta]$ for fraction EF3-10 was redetermined as $194 \mathrm{~cm}^{3} \mathrm{~g}^{-1}$. In the same figure, the $[\eta]-M_{w}$ data for acetone and THF solutions, obtained in our previous study, ${ }^{8}$ are shown by triangles and rectangles, respectively. The following MarkHouwink-Sakurada (MHS) equation is established for DMAc solutions by the least-squares method:

$$
\begin{aligned}
& \quad[\eta]=1.34 \times 10^{-2} M_{w}^{0.82} \\
& \quad\left(\mathrm{~cm}^{3} \mathrm{~g}^{-1}\right)\left(\text { in DMAc at } 25^{\circ} \mathrm{C}\right)
\end{aligned}
$$

Obviously, $[\eta]$ is highest in DMAc and lowest in THF. The exponent $a$ in the MHS equation

$$
[\eta]=K_{m} M_{w}{ }^{a}
$$

$\left(K_{m}\right.$ and $a$ are parameters characteristic of the polymer/solvent combination at a given temperature) increases in the order: acetone $<$ THF $<$ DMAc. In our previous studies, ${ }^{8,12}$ the values of $M_{w}$ for some of the CDA fractions used here were determined by LS in acetone and THF and by GPC in THF and are aslo listed in Table I. We see that the $M_{w}$ values in the three solvents (acetone, THF, and DMAc) are almost the same. This indicates that the CDA molecule does not associate in these solvents and that the light scattering technique established for the cellulose acetate is very reliable, at least, $M_{w}$ is concerned. Further reference will be made to this point later. We note that most of the data in acetone and THF given in Table I were obtained by other research personnel at our laboratory and the $M_{w}$ and $\left\langle S^{2}\right\rangle_{z}^{1 / 2}$ data on sample EF38 (in acetone) were obtained by research personnel at the Institute for Chemical Research, Kyoto University, Kyoto. From Figure 1b, we obtained the following empirical relation:

$$
\left\langle S^{2}\right\rangle_{z}^{1 / 2}=0.68 \times 10^{-8} M_{w}^{0.53} \quad(\mathrm{~cm})
$$


Dilute Solution Properties of CDA/DMAc

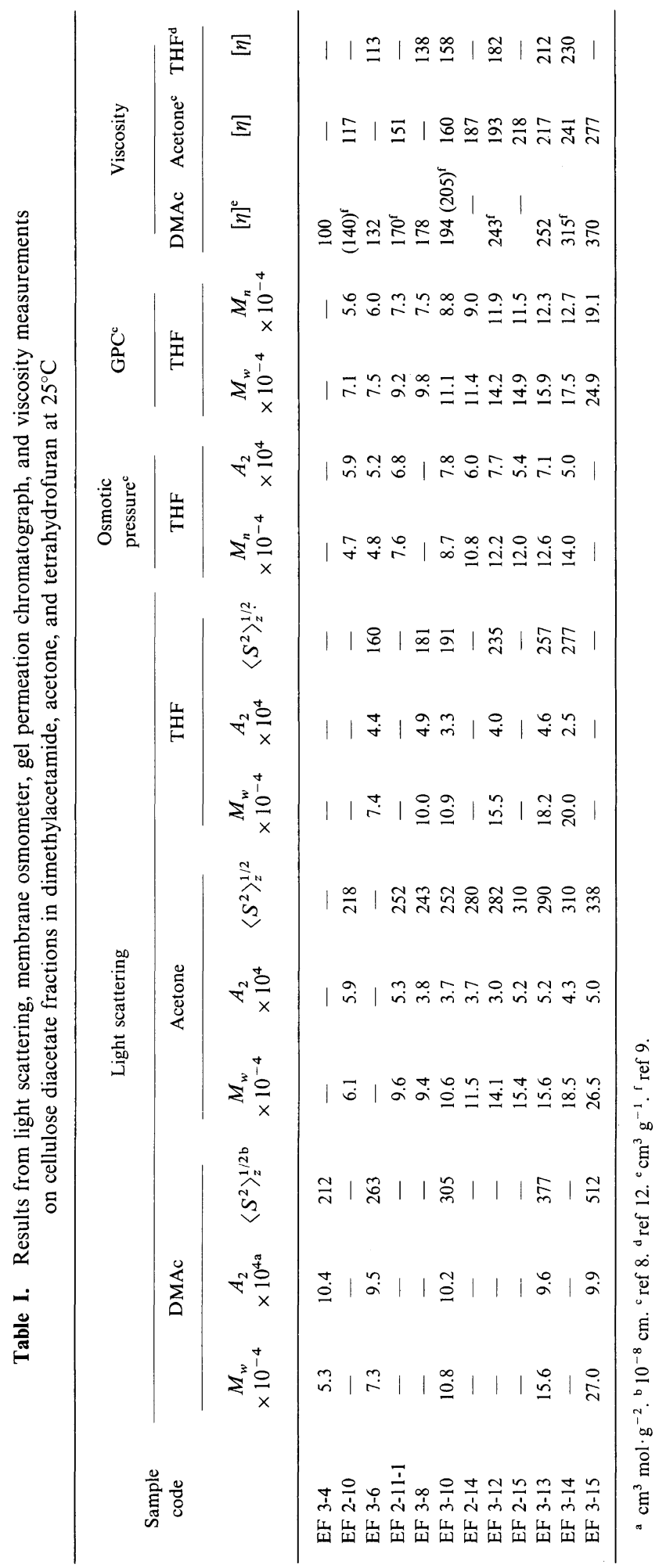




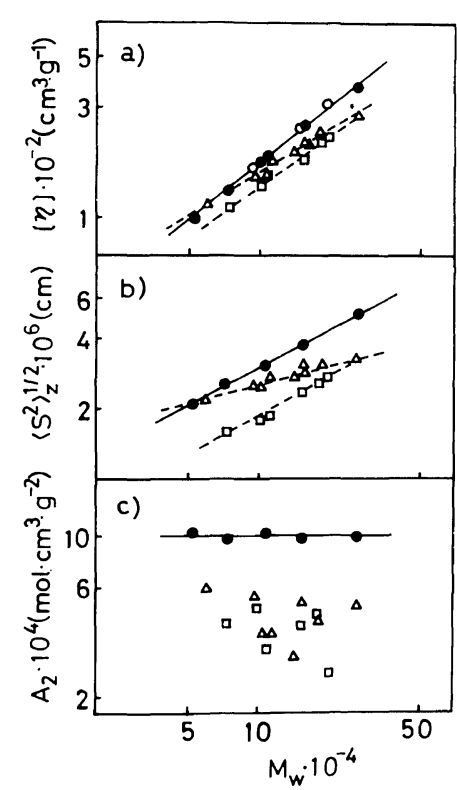

Figure 1. Molecular weight dependence of limiting viscosity number [ $\eta]$ (a), $z$-average radius of gyration $\left\langle S^{2}\right\rangle_{z}^{1 / 2}$ (b) and the second virial coefficient $A_{2}$ (c) for cellulose acetate $(\mathrm{DS}=2.46)$ in dimethylacetamide (circle), acetone (triangle $)^{8}$ and tetrahydrofuran (rectangle $)^{8}$; open circle, Kamide et $a .^{9}{ }^{9}\left(M_{w}\right.$ was determined in acetone and tetrahydrofuran); closed circle, present work.

in DMAc at $25^{\circ} \mathrm{C}$. The exponent 0.53 is intermediate between the value in acetone (0.308) and that in THF (0.558). Figure 1c shows that $A_{2}$ is almost independent of $M_{w}$. The $A_{2}$ values in DMAc are approximately twice those in acetone and THF. ${ }^{8}$

The values of Flory's viscosity parameter $\Phi$ calculated from the $[\eta],\left\langle S^{2}\right\rangle_{z}^{1 / 2}$, and $M_{w}$ data in DMAc are shown in Table II and Figure 2a, along with those in acetone and THF. ${ }^{8}$ Here the Schulz-Zimm distribution was assumed for all fractions, whose polydispersity indices $M_{w} / M_{n}$ were 1.25 on the average. ${ }^{8}$ It is evident that $\Phi$ depends significantly on molecular weight, and may be expressed as

$$
\Phi=5.15 \times 10^{21} M_{w}{ }^{0.23}
$$

We note that the $\Phi$ value even for the highestmolecular weight fraction studied is about $70 \%$ smaller than the theoretical value $2.87 \times 10^{23}$ for non-draining Gaussian coils. The $\Phi$ values in DMAc are much smaller than those in acetone and THF, as can be seen from Figure 2a. Interestingly, $\Phi$ increases in the order of decreașing solvent
Table II. Flory's viscosity parameter $\Phi$, linear expansion factor $\alpha_{\mathrm{s}}$, and draining parameter $X$ for cellulose diacetate in dimethylacetamide at $25^{\circ} \mathrm{C}$

\begin{tabular}{lcccc}
\hline $\begin{array}{c}\text { Sample } \\
\text { code }\end{array}$ & $M_{w} \times 10^{-4}$ & $\Phi \times 10^{-23}$ & $\alpha_{\mathrm{s}}$ & $\begin{array}{c}X \text { (by method } \\
1 \mathrm{~A})\end{array}$ \\
\hline EF3-4 & 5.3 & 0.59 & 1.02 & 0.45 \\
EF3-6 & 7.3 & 0.57 & 1.02 & 0.43 \\
EF3-10 & 10.8 & 0.79 & 1.03 & 0.72 \\
EF3-13 & 15.6 & 0.79 & 1.03 & 0.71 \\
EF3-15 & 27.0 & 0.80 & 1.04 & 0.74 \\
\hline
\end{tabular}

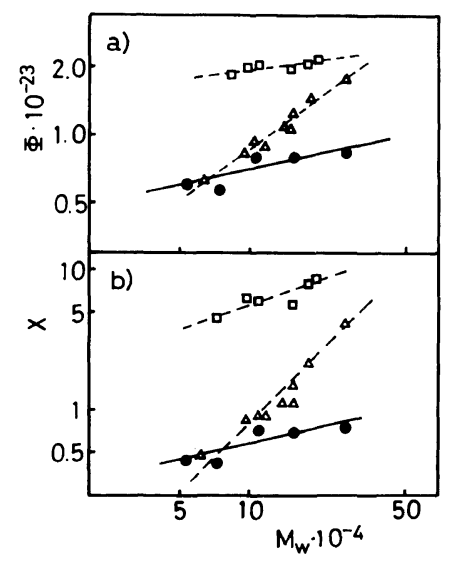

Figure 2. Molecular weight dependence of Flory viscosity parameter $\Phi(\mathrm{a})$, and the draining parameter $X$ (b) for cellulose acetate ( $\mathrm{DS}=2.46)$ in dimethylacetamide (circle), acetone (triangle $)^{8}$ and tetrahydrofuran (rectangle) ${ }^{8}$.

polarity: DMAc $<$ acetone $<$ THF.

The linear expansion factor $\alpha_{s}\left(=\left\langle S^{2}\right\rangle^{1 / 2} /\right.$ $\left\langle S^{2}\right\rangle_{0}^{1 / 2} ;\left\langle S^{2}\right\rangle_{0}^{1 / 2}$ is the radius of gyration in the unperturbed state) was estimated from the present data for $M_{w}, A_{2}$, and $\left\langle S^{2}\right\rangle_{z}^{1 / 2}$ in DMAc, using the approximate expression of Kurata-FukatsuSotobayashi-Yamakawa (KFSY) for the penetration function $\psi\left(\equiv A_{2} / 4 \pi^{3 / 2} N_{\mathrm{A}}\left(\left\langle S^{2}\right\rangle^{3 / 2} / M^{2}\right) ; N_{\mathrm{A}}\right.$ is the Avogadro constant). ${ }^{22}$ The estimated $\alpha_{\mathrm{s}}$ values are summarized in the fourth column of Table II. Using the $\Phi$ and $\alpha_{\mathrm{s}}$ data, the draining parameter $X$ can be determined by Method 1A described previously ${ }^{4}$ and can be compared with those in acetone $(X=1.48)$ and THF (6.6). ${ }^{8}$ It should be noted that method $1 \mathrm{~A}$ is based on the Kurata-Yamakawa (KY) theory ${ }^{23}$ which assumes that $a_{2}\left(\equiv d \ln \left(\left\langle S^{2}\right\rangle_{0}\right)\right.$ 
$M)(d \ln M)=0$ in the unperturbed state. However, the CDA chain in acetone is non-Gaussian (i.e., $a_{2}<0$ ). Thus $X$ for CDA in acetone evaluated by method 1A might be less accurate, but the values evaluated by other methods $1 \mathrm{~B}$ and $1 \mathrm{E}^{4}$ lie between $0.2-0.3$, and are much smaller than approximate values at the non-draining limit $(20-50)$. The $X$ value for CDA in DMAc is the smallest among the three solvents in which the draining effect can not be ignored as was found for most of the other cellulose derivatives. ${ }^{4,5,7-9,17}$

When $a_{2}=0, X$ can be expressed by

$$
X=(3 / 2 \pi)^{1 / 2}\left(d / a^{\prime}\right) N^{1 / 2}
$$

where $d$ is the hydrodynamic diameter of a segment of length $a^{\prime}$ and $N$ is the number of segments in the molecule. If we assume a molecular chain model, $a^{\prime}$ and $N$ can be separately evaluated and $d$ from $X$ data alone.

Another approach for evaluating $d$ when $X$ is unknown is to use the first-order perturbation theory for volume effect ${ }^{24}$ :

$$
\begin{aligned}
& \left(\alpha_{\mathrm{s}}{ }^{2}-1\right) /[1-(\Theta / T)] \\
& \quad=(134 / 105)(6 / \pi)^{1 / 2}\left(d / a^{\prime}\right)^{3} N^{1 / 2}
\end{aligned}
$$

where $\Theta$ is Flory's theta temperature and $T$ is the temperature, both expressed in $K$. Equation 3 is valid only in the vicinity of $\alpha_{\mathrm{s}} \simeq 1$, but should hold for cellulose derivative solutions. ${ }^{4,8,9,15,17}$ Substitution of the experimental values for $\alpha_{\mathrm{s}}, \Theta$, and $T$ into eq 3 makes it possible to determine the $d$ value, if $a^{\prime}$ and $N$ are known in advance.

The hydrodynamical segment is conventionally assumed to be equivalent to the statistical chain segment (the statistical chain model) or to the monomer unit (the simple equivalent chain model). On the basis of these two molecular chain models, $a^{\prime}$ and $N$ can be estimated.

For a statistical chain model,

$$
a^{\prime}=A^{2} m_{0} / l
$$

and

$$
N=M /\left(A m_{0} / l\right)^{2}
$$

where $A$ is the unperturbed chain dimensions, $l$ (=6.15 $\AA$ for CDA) and $m_{0}$ (=264 for CDA) are the length and the molecular weight of the monomer unit, respectively.

For a simple equivalent chain model,

$$
a^{\prime}=l
$$

and

$$
N=M / m_{0}
$$

It may be expected that if the $X$ values obtained in this study (Table II) are reasonable, the $d$ values evaluated from $X$ data (eq 2) should agree fairly well with those obtained by the thermodynamical method (eq 3). In order to confirm this expectation, the experimental data on CDA sample EF3-8 $\left(M_{w}=9.4 \times 10^{4}\right)$ in acetone were analyzed. The $X$ value for this sample was determined to be 0.95 by method 1A from Table II of ref 12, and $\alpha_{\mathrm{s}}$ was

\begin{tabular}{|c|c|c|c|c|c|c|c|c|c|c|}
\hline \multirow{4}{*}{ Polymer } & \multirow{4}{*}{ Solvent } & \multirow{4}{*}{ Sample } & \multirow{4}{*}{$M_{w} \times 10^{-4}$} & \multirow{4}{*}{$X_{\mathbf{E}}^{\mathbf{a}}$} & \multicolumn{6}{|c|}{$d \times 10^{8} / \mathrm{cm}$} \\
\hline & & & & & \multicolumn{3}{|c|}{ Statistical chain model } & \multicolumn{3}{|c|}{$\begin{array}{c}\text { Simple equivalent chain } \\
\text { model }\end{array}$} \\
\hline & & & & & \multicolumn{2}{|c|}{ eq $2,4,5$} & \multirow{2}{*}{ q $3,4,5$} & \multicolumn{2}{|c|}{ eq $2,4^{\prime}, 5^{\prime}$} & \multirow{2}{*}{$3,4^{\prime}, 5$} \\
\hline & & & & & $X=X_{\mathrm{E}}$ & $X=20$ & & $X=X_{\mathrm{E}}$ & $X=20$ & \\
\hline \multirow{2}{*}{ CDA } & Acetone $^{b}$ & EF3-9 & 9.6 & 0.95 & 33.5 & 712 & 24.6 & 0.5 & 9.5 & 3.0 \\
\hline & DMAc & EF3-13 & 15.6 & 0.71 & 37.0 & 1047 & - & 0.3 & 7.3 & - \\
\hline Polystyrene ${ }^{c}$ & Cyclohexane & HB2-3 & 320 & 33.1 & 9.3 & 5.6 & $7.3^{\mathrm{d}}$ & 0.3 & 0.2 & 1.6 \\
\hline
\end{tabular}
calculated to be 1.02 at $25.4^{\circ} \mathrm{C}$. We also estimated $\Theta$ (in this case, the lower critical solution temperature $\left.\Theta_{\mathrm{LCST}}\right)$ to be about $163^{\circ} \mathrm{K}$ for sample EF3-8 in acetone by analyzing the temperature dependence

Table III. Evaluation of hydrodynamical segment diameters of cellulose diacetate and polystyrene

${ }^{a} X$ values estimated by method 1 A using experimental data. ${ }^{b}$ ref $8 .{ }^{c}$ ref $25 .{ }^{d}$ ref 23 . 
of $A_{2}{ }^{16}$ and also $A$ to be $1.6 \AA$ at same temperature by method $2 \mathrm{~B}$ (see eq 6 ). The results are shown in Table III. Here the $d$ value corresponding to $X=20$ is included for comparison.

Even though rather large experimental errors involved in the determination of $\Theta_{\mathrm{LCST}}$ for CDA in acetone, the $d$ values determined on the basis of the statistical chain segment model by these two different methods are quite consistent. The use of $X=$ 20 in eq 2 yields an unreasonably large $d$ value, nearly 30 times larger than the $d$ value $(24.6 \AA)$ obtained by the thermodynamic method. This indicates that the draining effect cannot be neglected and that the $X$ values determined in this study are reliable. In addition, the simple equivalent chain model, along with eq 2 , affords us with an unexpectedly smaller $d$ value $(0.5 \AA)$. Kurata and Yamakawa have shown for polystyrene in cyclohexane that the draining effect is negligible (i.e., $X \gtrsim 20$ ) and that the statistical chain model gives the segment size a more reasonable value than the simple equivalent chain model. ${ }^{23} \mathrm{We}$ analyzed the same literature data ${ }^{25}$ used by Kurata and Yamakawa, ${ }^{23}$ and summarized the results in Table III, which confirm the validity of their conclusion.

Using the $X$ (Table II) and $A$ (Table IV) data for a CDA sample EF3-13 in DMAc, we determined the $d$ value on the statistical chain segment model by eq 2 to be $37 \AA$, which is about the same as that in acetone, being five times larger than the molecular diameter of a glucopyranose unit, crystallographically determined. ${ }^{26}$. The $d$ value obtained on the statistical chain model by neglecting the draining effect for CDA in DMAc is more than $700 \AA$, as in the case of CDA in acetone. This is too large to be accepted as the diameter of a hydrodynamical segment. As long as the statistical chain model is employed, the draining effect should not be neglected.

As will be shown later, cellulose and cellulose derivatives dissolved in solvents with appreciable solvation, ${ }^{13,27-29}$ and this is considered to be responsible for the serious discrepancy between $d$ and the actual molecular diameter. The values of $d$ for other CDA fractions in DMAc were estimated to be in the range from 30 to $45 \AA$, on the basis of the statistical chain model. These values are not too large, but exceed those anticipated from preliminary experiments on solvation. ${ }^{21}$ Thus a more detailed examination must be made.

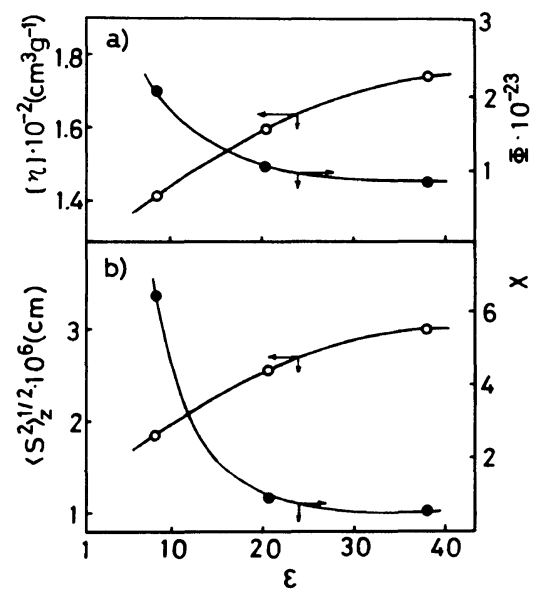

Figure 3. Effect of the dielectric constant of the solvent $\varepsilon$ on limiting viscosity number $[\eta]$, Flory's viscosity parameter $\Phi$ (a) and the $z$-average radius of gyration $\left\langle S^{2}\right\rangle_{z}^{1 / 2}$, the draining parameter $X$ (b) for cellulose acetate $(\mathrm{DS}=2.46):[\eta]$ and $\left\langle S^{2}\right\rangle_{z}^{1 / 2}$ are for the polymer with $M_{w}=1 \times 10^{5}$.

When $a_{2}$ is not zero, $d$ cannot be determined simply from eq 2 , since the coefficient appearing in this equation should differ from $(6 / \pi)^{1 / 2}$, judging from eq C.10 in ref 23. Thus, the deduction of the correct $d$ for cellulose derivatives is even now open for a further study.

Figures $3 a-3 b$ illustrate the effects of the dielectric constant $\varepsilon$ of the solvent on $[\eta],\left\langle S^{2}\right\rangle_{z}^{1 / 2}$, and $X$ for CDA with $M_{w}=1 \times 10^{5}$. We have already shown similar plots for cellulose acetates $(\mathrm{DS}=0.49) .{ }^{15} \mathrm{An}$ increase in $\varepsilon$ leads to larger values for $[\eta]$ and $\left\langle S^{2}\right\rangle_{z}^{1 / 2}$ and smaller values for $X$ and $\Phi$.

The unperturbed chain dimensions $A\left(\equiv\left(\left\langle R^{2}\right\rangle_{0}\right)\right.$ $M)^{1 / 2} ;\left\langle R^{2}\right\rangle_{0}$, the mean-square end-to-end distance of the chain in the unperturbed state) were estimated by using methods $2 \mathrm{~B}, 2 \mathrm{C}, 2 \mathrm{E}, 2 \mathrm{~F}$, and $2 \mathrm{G}$, proposed in a previous paper. ${ }^{4}$ Equations basic to these methods are as follows:

Method 2B:

$$
\left\langle S^{2}\right\rangle_{0}^{1 / 2}=\left\langle S^{2}\right\rangle^{1 / 2} / \alpha_{s}
$$

Method 2C:

$$
\left\langle S^{2}\right\rangle^{3 / 2} / M^{3 / 2}=A^{3} / 6^{3 / 2}+\left(1 / 4 \pi^{3 / 2}\right) B M^{1 / 2}
$$

(where $B$ is the long-range interaction parameter)

Method 2E: 


$$
[\eta] / M^{1 / 2}=K+2(3 / 2 \pi)^{3 / 2} \Phi_{0}(\infty) B M^{1 / 2}
$$

(where $K=\Phi_{0}(\infty) A^{3}, \Phi_{0}(\infty)=2.87 \times 10^{23}$ )

Method 2F:

$-\log K_{m}+\log \left(1+2\left((a-0.5)^{-1}-2\right)^{-1}\right)$

$=-\log K+(a-0.5) \log M_{0}$

(where $M_{0}$ is a parameter depending on the molecular weight range, $M_{1}-M_{2}$, in which the MHS equation can be applied)

Method 2G:

$$
\begin{gathered}
{[\eta] / M^{1 / 2+a_{\Phi}+3 / 2 a_{2}}=6^{3 / 2} K_{\Phi} K_{0}^{3 / 2}} \\
\quad+0.66 K_{\Phi} B M^{\left(1-3 a_{2}\right) / 2}
\end{gathered}
$$

(where $K_{0}=\left(\left\langle S^{2}\right\rangle_{0} / M\right) M^{a_{2}}, K_{\Phi}=\Phi / M^{a_{\Phi}}$ )

Figure 4 shows $\left\langle S^{2}\right\rangle_{0} / M_{w}$ for CDA in DMAc obtained by Method $2 \mathrm{~B}$ and those for the same polymer in acetone and THF. Evidently, $\left\langle S^{2}\right\rangle_{0} / M_{w}$ for the CDA/DMAc system is constant, indicating that the CDA in DMAc is Gaussian. Figure 5a$5 d$ show plots constructed for the CDA in DMAc according to eq 7-10. Here the filled and unfilled circles indicate the data in the present and previous studies, respectively.

Table IV presents the values of $A$ and $B$ estimated from eq 6-10 and also includes the values of the conformation parameter, $\sigma$, defined by

$$
\sigma=\left\langle S^{2}\right\rangle_{0}^{1 / 2} /\left\langle S^{2}\right\rangle_{0, \mathrm{f}}^{1 / 2}=A / A_{\mathrm{f}}
$$

and the characteristic ratio $C_{\infty}$

$$
C_{\infty}=A_{\infty}{ }^{2} m_{0} / l^{2}
$$

where $\left\langle S^{2}\right\rangle_{0, \mathrm{f}}^{1 / 2}\left(=6^{-1 / 2} A_{\mathrm{f}} M^{1 / 2}\right)$ is the root-meansquare radius of gyration of a hypothetical freely rotating chain with $A_{\mathrm{f}}=0.476 \times 10^{-8} \mathrm{~cm}$. The molecular weight dependence of $\Phi$ for CDA in DMAc

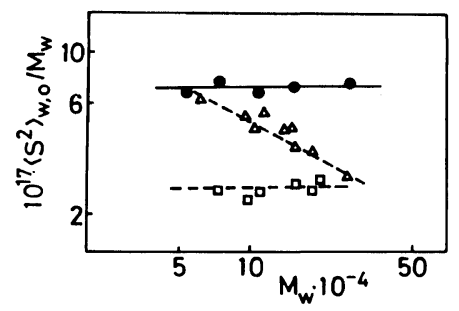

Figure 4. Molecular weight dependence of the ratio of $\left\langle S^{2}\right\rangle_{0, w} / M_{w}$ for cellulose acetate (DS=2.46) in dimethylacetamide (circle), acetone (triangle) ${ }^{8}$ and tetrahydrofuran (rectangle) ${ }^{8}$. is appreciable $\left(a_{\Phi}=0.23\right)$. Thus, methods $2 \mathrm{E}$ and $2 \mathrm{~F}$ underestimate $A$ significantly, and the most probable $A$ value should be the average $\left(1.98 \times 10^{-8}\right.$ $\mathrm{cm}$ ) of those determined by methods $2 \mathrm{~B}, 2 \mathrm{C}$, and 2G. ${ }^{4,8,9,15,17}$ In a previous paper, ${ }^{9}$ we obtained $A=$

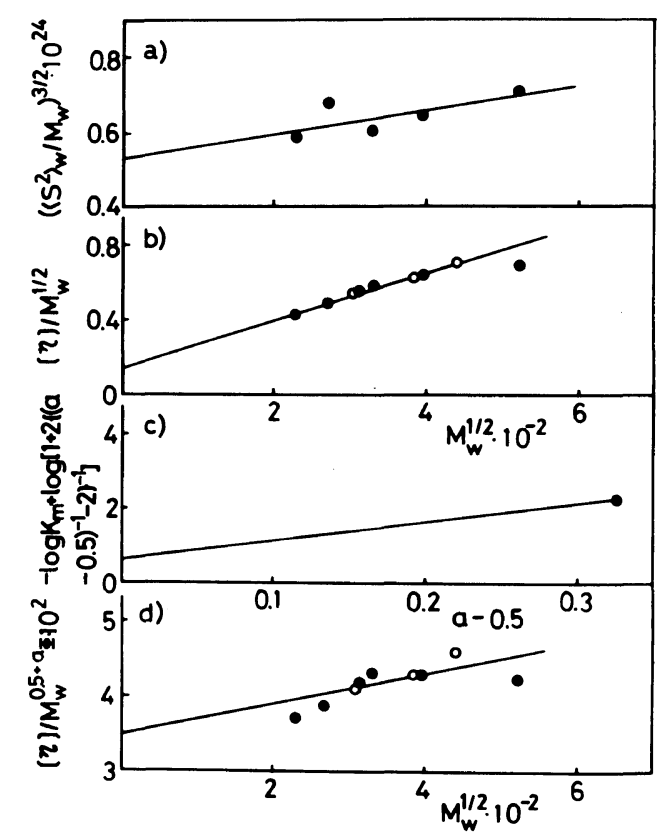

Figure 5. Baumann plot (a), Stockmayer-Fixman plot (b), Kamide et al. plot (c), Kamide-Miyazaki (I) plot (d) for cellulose acetate $(\mathrm{DS}=2.46)$ in acetone at $25^{\circ} \mathrm{C}$ : present work; $\bigcirc$, Kamide et al. ${ }^{9}\left(M_{w}\right.$ was determined in acetone and tetrahydrofuran).

Table IV. Unperturbed chain dimensions

$A$, long-rang interaction parameter $B$, conformation parameter $\sigma$, and characteristic ratio $C_{\infty}$ of cellulose diacetate in dimethylacetamide at $25^{\circ} \mathrm{C}$

\begin{tabular}{lccccc}
\hline \multirow{2}{*}{ Method } & $A \times 10^{8}$ & & $B \times 10^{27}$ & & \\
\cline { 2 - 3 } \cline { 5 - 6 } & $\mathrm{cm}$ & & $\mathrm{cm}^{3}$ & & $C_{\infty}$ \\
\hline $2 \mathrm{~B}\left(\alpha_{\mathrm{s}}\right.$ from $\left.\psi\right)$ & 2.05 & & - & 4.33 & 37.6 \\
$2 \mathrm{C}\left(a_{2}=0\right)$ & 1.98 & & 6.97 & 4.16 & 34.7 \\
$2 \mathrm{E}\left(a_{2}=a_{\Phi}=0\right)$ & 0.79 & & 6.90 & 1.66 & 5.53 \\
$2 \mathrm{~F}\left(a_{2}=a_{\Phi}=0\right)$ & 0.92 & & - & 1.93 & 7.50 \\
$2 \mathrm{G}\left(a_{\Phi} \neq 0\right)$ & 1.90 & & 5.09 & 3.99 & 32.0 \\
\hline $\begin{array}{l}\text { Most probable } \\
\text { value }\end{array}$ & 1.98 & - & 4.16 & 34.7 \\
\hline
\end{tabular}


Table V. Various solution parameters of cellulose diacetate $(\mathrm{DS}=2.46)$ in dimethylacetamide, acetone, and tetrahydrofuran at $25^{\circ} \mathrm{C}$

\begin{tabular}{lccccccccc} 
Solvent & $\begin{array}{c}\text { Dielectric } \\
\text { constant } \varepsilon\end{array}$ & $K_{m}$ & $a$ & $a_{\Phi}$ & $a_{2}$ & $a_{1}$ & $\begin{array}{c}A \text { (most probable) } B \text { (by method } 2 \mathrm{G}) \\
\left(10^{-8} \mathrm{~cm}\right)\end{array}$ & $\begin{array}{l}\sigma \\
\left(10^{-27} \mathrm{~cm}^{3}\right)\end{array}$ \\
\hline DMAc $_{\text {Acetone }}^{\mathrm{a}}$ & 37.8 & 0.0134 & 0.82 & 0.23 & 0 & 0.09 & 1.98 & 5.09 & 4.16 \\
THF $^{\mathrm{a}}$ & 20.7 & 0.133 & 0.62 & 0.716 & -0.471 & 0.107 & 1.73 & 1.53 & 3.59 \\
0.2 & 0.0513 & 0.69 & 0.105 & 0 & 0.083 & 1.23 & 2.11 & 2.56 \\
\hline
\end{tabular}

a ref 8 .

\section{$2.27 \times 10^{-8} \mathrm{~cm}$ for a CDA fraction (EF3-11) in} DMAc by using method $2 \mathrm{~B}$. This value is somewhat larger than the most probable $A$ value.

Table V summarizes the values of $K_{m}, a, a_{\Phi}, a_{2}, a_{1}$ $\left(\equiv a-1 / 2-3 / 2 a_{2}-a_{\Phi}\right), A, B$, and $\sigma$ for CDA in DMAc, acetone, and THF. The CDA chain in acetone is non-Gaussian even in the unperturbed state $\left(a_{2}<0\right){ }^{8}$ It should be noted that negative values of $a_{2}$ have been observed not only for CDA in acetone but also for cellulose, amylose and their derivatives. $^{4,15,17}$ These $a_{2}$ may be ascribed to solvation whose extent varies with molecular weight. ${ }^{13}$ When $a_{2}<0$, methods $2 \mathrm{C}, 2 \mathrm{E}$ and $2 \mathrm{~F}$ are evidently inapplicable. Kamide and his coworkers have proposed a thermodynamic method (method 2D) and hydrodynamic methods (method $2 \mathrm{G},{ }^{4} 2 \mathrm{~J},{ }^{5} 2 \mathrm{~K},{ }^{17}$ and $2 \mathrm{~L}^{21}$ ) for estimating $A$ of macromolecules with $a_{2} \neq 0$ and $a_{\Phi} \neq 0$. They showed that these methods are quite applicable to cellulose and amylose derivatives and that the results derived therefrom and method $2 \mathrm{~B}^{4,5,17,21}$ agree well. The most probable $A$ values in Table $\mathrm{V}$ are the average of values determined by methods $2 \mathrm{~B}, 2 \mathrm{D}$, and $2 \mathrm{G}$, for acetone and values obtained by methods $2 \mathrm{~B}, 2 \mathrm{C}$, and $2 \mathrm{G}$ for THF. The value of $A$ for acetone in Table $\mathrm{V}$ agrees with those determined by methods $2 \mathrm{~J}, 2 \mathrm{~K}$, and $2 \mathrm{~L}$ $\left(1.72,1.76\right.$, and $1.80 \times 10^{-8} \mathrm{~cm}$, respectively). ${ }^{17,21}$

The dependence of $A$ and $\sigma$ on the dielectric constant $\varepsilon$ of the solvent is illustrated in Figure 6 . Both $A$ and $\sigma$ increase with increasing $\varepsilon$, which confirms that the CDA chain becomes less flexible when dissolved in a more polar solvent. Recently, we found a similar correlation between $A$ and $\sigma$ for cellulose acetate with $\mathrm{DS}=0.49 .{ }^{15}$ Thus, the equilibrium rigidity of the cellulose acetate chain is not intrinsic.

Figure 7 shows the correlation between $A$ and the chemical shift $\delta_{\mathrm{CH}_{3}}$ of the $O$-acetyl methyl group or $\delta_{\mathrm{OH}}$ of the hydroxyl group for CDA. The data

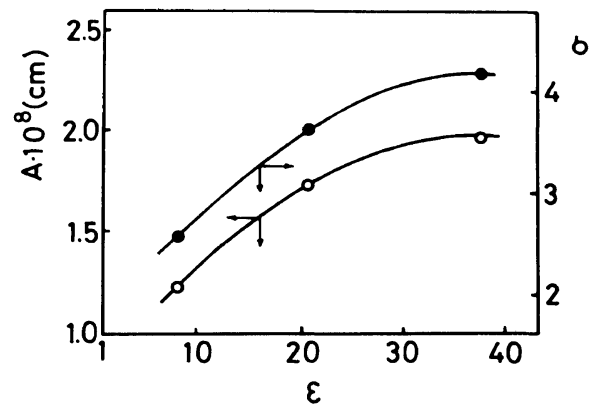

Figure 6. Effect of the dielectric constant of the solvent $\varepsilon$ on the unperturbed chain dimension $A$ and conformation parameter $\sigma$ for cellulose acetate $(D S=2.46)$.

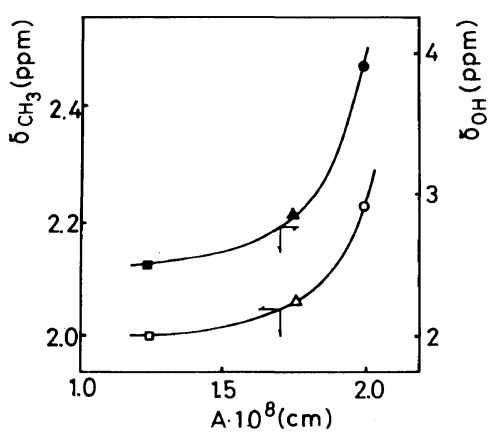

Figure 7. Correlation between the chemical shift of $O$ acetyl methyl group $\delta_{\mathrm{CH}_{3}}$ (open mark), hydroxyl group $\delta_{\mathrm{OH}}$ (closed mark) and the unperturbed chain dimension $A$ for cellulose acetate (DS $=2.46)$ in dimethylacetamide (circle), acetone (triangle), and tetrahydrofuran (rectangle).

except for DMAc were taken from the literature. ${ }^{13}$ Figure 7 makes it evident that $A$ is correlated closely with interactions between the functional groups and the solvent. This interaction is stronger in a polar solvent and can be considered evidence for the occurence of "solvation." Further experimental 
evidence for this is that the compressibility of the solution is lower than that of the solvent; our recent study on solvation of CDA in various solvents have shown that the extent of solvation, expressed in terms of the number of solvated molecules per unit weight of the polymer, increases as the polarity of solvent increases: DMAc $>$ acetone $>$ THF. ${ }^{21}$ In other words, CDA behaves as a solvated molecule and the solvent effect on $A$ can be ascribed to an increase in local steric hindrance resulting from strong interaction for cellulose acetates whose DS is below $2 .{ }^{15}$ It is reported that most cellulose derivatives ${ }^{27-29}$ solvate in polar solvents.

When compared with the other two solvents, acetone is a rather specific solvent for CDA, giving an unusually large positive $a_{\Phi}$ and a large negative $a_{2}$. This solvent is not very suitable for light scattering measurements, since difficulties in removing gellike materials are attendant on light scattering, as has been discussed by many researchers. ${ }^{3,8,30} \mathrm{We}$ obtained almost the same $M_{w}$ values for CDA solutions in three different solvents. The $\left\langle S^{2}\right\rangle_{z}^{1 / 2}$ value of $234 \AA$ for fraction EF3-8 in acetone at $25.4^{\circ} \mathrm{C}$ determined in Kyoto University can be compared with the value $(251 \AA)$ calculated from the empirical equation $\left\langle S^{2}\right\rangle_{z}^{1 / 2}=7.38 \times 10^{-8}$ $M_{w}^{0.308}(\mathrm{~cm})$, which was established for other CDA samples in acetone at $25^{\circ} \mathrm{C}$ in our laboratory. ${ }^{8}$ Nevertheless, the slight possibility of that gel-like materials remain in acetone solutions of CDA with a relatively high $M_{w}$ cannot completely be ruled out since the radius of gyration is much more susceptible to the presence of gel-like materials than the molecular weight, and if this is exactly what happens in an actual system, $a_{\Phi}$ and $a_{2}$ for CDA in acetone would be erroneously estimated. A complete explanation of the specific nature of acetone for celulose acetate is still lacking.

In summary, the specific interaction occuring between the $O$-acetyl group in the CA molecule and the solvent molecule is strong and the number of solvated molecules per repeating unit of the polymer is large when CA (DS $=2.46)$ is dissolved in a polar solvent. Solvation leads to a large $A$. In consideration of this, "two-parameter theory" is not valid for CDA solutions. We obtained the following molecular parameters by extrapolating the data in Figure 3 and 6 to $\varepsilon=1, X>50, \Phi \simeq 3 \times 10^{23}$, $A \simeq 0.8 \AA, \sigma=1.2$. These values suggest that if no solvation occurs, cellulose diacetate (and probably all cellulose derivatives) should not be semiflexible, in contrast to other rigid polymers.

\section{REFERENCES}

1. K. Kamide, S. Manabe, and E. Osafune, Makromol. Chem., 168, 173 (1973).

2. K. Kamide, T. Terakawa, and S. Manabe, Sen- $i$ Gakkaishi, 30, T-464 (1974).

3. K. Kamide, T. Terakawa, S. Manabe, and Y. Miyazaki, Sen-i Gakkaishi, 31, T-410 (1975).

4. K. Kamide and Y. Miyazaki, Polym. J., 10, 409 (1978).

5. K. Kamide and Y. Miyazaki, Polym. J., 10, 539 (1978).

6. K. Kamide and T. Terakawa, Polym. J., 10, 559 (1978).

7. S. Ishida, H. Komatsu, T. Terakawa, Y. Miyazaki, and K. Kamide, Mem. Fac. Eng., Kanazawa Univ., 12, 103 (1979).

8. K. Kamide, T. Terakawa, and Y. Miyazaki, Polym. J., 11, 285 (1979).

9. K. Kamide, Y. Miyazaki, and T. Abe, Polym. J., 11, 523 (1979).

10. K. Kamide, Y. Miyazaki, and T. Abe, Makromol. Chem., 180, 2801 (1979).

11. H. Suzuki, Y. Miyazaki, and K. Kamide, Netsusokutei, 7, 37 (1980).

12. H. Suzuki, Y. Miyazaki, and K. Kamide, Eur. Polym. J., 16, 703 (1980).

13. K. Kamide, K. Okajima, and M. Saito, Polym. J., 13, 115 (1981).

14. K. Kamide and K. Okajima, Polym. J., 13, 127 (1981).

15. K. Kamide, M. Saito, and T. Abe, Polym. J., 13, 421 (1981).

16. H. Suzuki, K. Ohno, K. Kamide, and Y. Miyazaki, Netsusokutei, 8, 67 (1981).

17. K. Kamide and M. Saito, Eur. Polym. J., 17, 1049 (1981).

18. H. Suzuki, K. Kamide, and M. Saito, Polym. J., in press.

19. K. Kamide, K. Okajima, T. Matsui, and S. Manabe, Cellulose Chem. Technol., in press.

20. K. Kamide and M. Saito, Eur. Polym. J., in press.

21. K. Kamide and M. Saito, unpublished results.

22. M. Kurata, "Modern Industrial Chemistry III," Asakura, Tokyo, 1975, p 287.

23. M. Kurata and H. Yamakawa, J. Chem. Phys., 29, 311 (1958).

24. K. Kurata, H. Yamakawa, and E. Teramoto, J. Chem. Phys., 28, 785 (1958).

25. W. R. Krigbaum and D. K. Carpenter, J. Phys. Chem., 59, 1166 (1955).

26. D. W. Jones, J. Polym. Sci., 5, 519 (1950).

27. W. R. Moore and B. M. Tidwell, Makromol. Chem., 81, 1 (1965). 
28. W. R. Moore, J. Polym. Sci., C, No. 16, 571 (1967).

29. W. R. Moore, International Symposium on Solution Properties of Natural Polymers, Edinburgh, 1967.

30. see for example, M. Wales and.D. L. Swanson, J. Phys. \& Colloid Chem., 55, 203 (1951); L. H. Sperling and M. Easterwood, J. Appl. Polym. Sci., 4, 25 (1960), N. M. Bikales and L. Segal, Ed., "High
Polymers," Vol. V, Part IV, John Wily \& Sons, Inc., New York, 1971, p 433; V. J. Klenin and G. P. Denisova, J. Polym. Sci., Polym. Symp., No. 42, 1563 (1973); D. W. Tanner and G. C. Berry, J. Polym. Sci., Polym. Phys. Ed., 12, 941 (1974); K. D. Goeble and G. C. Berry, J. Polym. Sci., Polym. Phys. Ed., 15, 555 (1977). 